\title{
MADURAR COMO PERSONAS PARA SERVIR COMO PASTORES*
}

DOI: https://doi.org/10.52039/seminarios.v53i183.618

Autor: Juan María Uriarte Goiricelaya. Obispo de San Sebastián
El punto de partida, las tres etapas de maduración apostólica y humana de Francisco Javier. Madurez, que es concepto límite, en cuatro vectores: amar, trabajar, jugar y orar. Maduración en el caso de seminaristas y sacerdotes. Consideración de los fallos. Necesidad de bajar a la "bodega interior".

\section{Introducción: el itinerario interior de Javier}

Un cordial saludo a los Obispos, rectores y formadores reunidos en este lugar, verdadero «espacio ecológico» de la Iglesia.

El título de la conferencia que se me ha asignado es magnífico. El tema apasionante. Pocos santos ofrecen en su vida y en sus escritos un flanco tan abierto para internarnos en el itinerario humano y espiritual de este hombre excepcional que, por la acción de la gracia, alcanzó una unidad interior admirable.

Existen aproximaciones rigurosas y competentes al itinerario espiritual de este apóstol, en tantos capítulos testigo y modelo del pastor. El libro de \footnotetext{
2006).

* Ponencia pronunciada en el V Centenario de San Francisco Javier (Javier, 13 septiembre
} 
León-Dufour («Itinerario místico del apóstol») es una obra maestra. Georg. Sehurhammer ofrece asimismo, en su monumental trabajo, elementos muy valiosos. En cambio no parecen muy numerosos ni conocidos los estudios relativos a la estructura y evolución psicológica de nuestro Santo. Sin este apoyo, no me he sentido capacitado, desde mi pobre conocimiento de la figura de Javier, para responder a la ambición del título de la conferencia: «la maduración humana y espiritual de Francisco Javier». Intentarlo hubiera sido incurrir frívolamente en la tentación denominada «psicoanálisis salvaje» por su fundador. Vds. me dispensarán, pues, que deje para autores más competentes el seguimiento riguroso, admirativo, cariñoso y crítico de este proyecto. Vds. sabrán dispensarme de frustrar la expectativa que el título habrá suscitado.

En esta breve introducción me limitaré a señalar, de la mano de LeónDufour, las tres etapas de la maduración apostólica de Javier:

La primera, que se inicia a partir de su conversión (1533) se caracteriza «por su despertar a la vida apostólica. Durante siete años Dios le ense$\tilde{n}$ a a reconocer en cualquier circunstancia su rostro paternal y a darse sin reservas a los que acuden a él».

En la segunda etapa, a partir de que, el año 1541, recibe la misión como Nuncio Apostólico para las tierras de Oriente, «el apóstol de Cristo vive a imagen de su Señor, que siendo rico se hizo pobre, se humilló haciéndose siervo de todos, sufrió para ser fiel a Dios y a los hombres».

La tercera etapa se inicia en 1545, cuando Javier parte de las Indias al lejano Extremo Oriente. "La confianza (del apóstol) debe echar aún raíces más profundas; en la soledad más completa el hombre del Espíritu ha de pasar por la prueba suprema de la confianza: la muerte», acontecida el año 1552.

Tras este mínimo acto de reconocimiento de la figura de este apóstol y de una sincera confesión de mi incompetencia para rastrear su itinerario, quiero presentarles el núcleo del tema que voy a desplegar. Puede titularse así: «madurar como personas para servir como pastores».

Ya de partida dejo a un lado la descripción de la madurez espiritual y pastoral. Podéis encontrarla en cualquier tratado o diccionario de teología espiritual o de teología pastoral. Me ciño a la madurez psicológica coherente para vivir la espiritualidad y la actividad apostólica de un pastor. Renuncio asimismo a estudiar la interacción existente entre madurez psicológica y madurez espiritual y pastoral. Parto, sin embargo, de un doble postulado: 
Son dos realidades diferentes. Hay personas con muchas lagunas en su madurez humana que, por la acción del Espíritu, han llegado a un alto nivel teologal. Digámoslo más gráficamente: hay santos que son humanamente deficientes, incluso con tasas sensibles de neuroticidad o defectos caracterológicos importantes.

Madurez psicológica y madurez espiritual y pastoral interactúan mutuamente. "Sin una adecuada formación humana, la formación sacerdotal estaría privada de su fundamento necesario» (PDV 43). «El candidato llamado al celibato encontrará en la madurez afectiva una base firme para vivir la castidad con fidelidad y alegría» (PDV 44). Recíprocamente, la vida espiritual profunda y la experiencia pastoral auténtica maduran y enriquecen la humanidad del presbítero en algunos aspectos y le ayudan a asumir, positiva y productivamente, algunas de sus limitaciones humanas.

\section{MADUREZ PSICOLÓGICA, AFECTIVA, SEXUAL (PDV 43, 44, 72)}

\section{Un concepto utópico y necesario}

La madurez es un concepto límite. Ningún humano llega a la madurez plena. ¿Por qué? Los neurofisiólogos sostienen que un ser humano explota a lo largo de su vida sólo un $10 \%$ de sus potencialidades cerebrales. Lo mismo puede decirse de sus capacidades psicológicas. Pretender un despliegue «a tope» de nuestra vida psíquica en todas las direcciones resultaría no sólo extenuante, sino imposible. Vivir es elegir. Elegir es renunciar a muchas posibilidades para centrarnos en unas pocas. Quien no sabe elegir y renunciar malogra su vida en la dispersión y en el deseo infantil de quererlo todo.

Sin embargo, el concepto límite de la madurez es necesario porque nos señala el camino, es decir, la maduración, que es un proceso hacia la madurez. El concepto de madurez nos señala los vectores (las líneas de fuerza) de nuestra maduración. Ya el fundador del psicoanálisis señalaba dos: «Lieben und Arbeiten» (amar y trabajar). La escuela humanista americana (Allport, Maslow) completa esta enumeración. Los cuatro vectores de crecimiento son amar (to love), trabajar (to work), jugar (to play) y orar (to pray). 


\section{Perfil de la madurez psicológica}

Es bastante común identificar en el lenguaje ordinario madurez psicológica y madurez humana. Hablando en propiedad, la madurez humana es un concepto más amplio: entraña la madurez biológica, la psicológica, la profesional, la moral, etc.

La madurez psicológica por su parte engloba dentro de sí muchas dimensiones, entre ellas, la afectiva y la sexual. La madurez afectiva y la sexual no se identifican plenamente entre sí, aunque comparten áreas comunes. Con una imagen de la geometría, el círculo mayor sería el de la madurez psicológica, dentro de la cual estarían englobadas, entre otras, la madurez afectiva y la sexual como dos círculos menores secantes entre sí.

La madurez psicológica es un terreno complicado y deficientemente estudiado. Sin embargo, hay una convergencia entre los estudiosos al señalar algunos de sus caracteres mayores.

a) La capacidad de percibirse correctamente a sí mismo, con sus posibilidades y limitaciones. La ensoñación y el auto-menosprecio no son compatibles con la madurez. La madurez reclama una gran aproximación entre el «yo ideal» y el «yo real».

b) La madurez comporta una unidad interior. Las diversas instancias de su persona (la razón, el deseo, las pulsiones, los ideales) no forman en ella un conjunto caótico, sino un todo relativamente unificado. Este es un factor en el que insisten todos los especialistas. No confunden, sin embargo, este estado con la ausencia de conflictos. El hombre y la mujer tienen un dominio «no despótico, sino político» respecto de su fantasía, de sus pulsiones y de sus sentimientos (Aristóteles). "Un hombre que vive bajo el imperio de sus impulsos no es todavía hombre; uno que los sofoca no es ya hombre» (K. Schneider). Ha aprendido a elaborar sus conflictos sin refugiarse en la neurosis.

c) Pero la unidad interior no es sólo integración. Es también orientación unificada. El que una persona tenga una dirección, una opción neta y firme en su vida que de alguna manera le trascienda y el que las demás dimensiones estén orientadas a potenciar esta opción, es un componente esencial, nuclear de la madurez. Todas las dimensiones de la madurez, para mantener su unidad y coherencia necesitan una motivación unificadora, un «ceñidor de la unidad». Allport, 
Maslow, Vergote. V. Frank atribuyen a la Religión una especial aptitud motivadora y unificadora.

d) Es dimensión necesaria en la persona madura la capacidad de amar con un amor que ha traspasado el narcisismo y ha llegado a la capacidad oblativa.

e) Ser maduro psicológicamente entraña asimismo la adhesión estable a unos valores que trascienden la propia persona y el pequeño grupo (valores sociales, morales, fe religiosa). La carencia absoluta de estos valores es una grave psicopatía.

\section{Rasgos de la madurez afectiva}

En el ancho mundo de la madurez psicológica es una pieza inexcusable la madurez afectiva. Consiste en la capacidad para amar de modo intenso, estable y comprometido y para dejarse amar honesta y limpiamente (sin maniobras de seducción o dominación ni exclusivismos celotípicos desconfiados). Quien la posea está normalmente dispuesto a la entrega oblativa al otro, a la búsqueda de su verdadero bien y a la demanda respetuosa a él. Aprecia el agradecimiento, la estima, el afecto; pero no los exige ni los busca como un mendigo. Nunca condiciona a ellos su disponibilidad ni su servicio. Jamás encadena a los otros a su persona. Despierta en ellos la capacidad y el gusto por el amor oblativo.

El reverso de la madurez afectiva es, sobre todo en nuestro tiempo, el narcisismo. Esta inmadurez, intensamente favorecida por el talante de nuestro tiempo, lleva escondida en su corazón una duda lacerante: la persona no sabe si es o no digna de ser amada. Para despejar esta duda existencial se dedica empeñativamente a ofrecer a los demás una imagen amable y adorable de sí misma a través de la continua exhibición de éxitos y resultados. Trata de deslumbrar y asombrar a los demás. Necesita de esa imagen exitosa para decirse a sí mismo, una y otra vez, que vale. Pero nunca acaba de creérselo. Precisamente por ello es tan sensible a la desaprobación. Ella le remite a la duda fundamental que no puede superar. Se defiende de esta duda proyectándola hacia el entorno (no soy valorado en lo que soy, se me exige demasiado, no se confía en mí para dejar en mis manos las responsabilidades que merezco, las cosas que emprendo no van bien por falta de apoyos, etc.). 
En un documento de 1993, la Congregación para la Educación Católica, asesorada por buenos especialistas, se aproxima certeramente a este concepto difícil y poliédrico: una personalidad madura crea y mantiene la serenidad; vive relaciones amistosas que manifiestan comprensión y afabilidad; posee un constante autocontrol; se reconoce y acepta en sus propios límites; juzga equilibradamente la realidad de las personas y de los acontecimientos y se sitúa ante ellos activa y pacientemente.

Es preciso añadir que, en palabras de Juan Pablo II, «el candidato llamado al celibato encontrará en la madurez afectiva una base firme para vivir la castidad con fidelidad y alegría» (PDV 44). Cuando la inmadurez es notable, el celibato no hace sino reflejarla y ahondarla. Cuando existen algunos aspectos de inmadurez, el celibato sincera y noblemente aceptado puede compensarlos en parte. Cuando la madurez es aceptable, el celibato le confiere un sello que lo embellece humanamente.

\section{Caracteres de la madurez sexual}

a) La madurez sexual tiene una dimensión biológica, a la que ordinariamente se accede en el umbral mismo de la juventud. Acabada la pubertad, órganos, secreciones, conductas, hormonas, aseguran la sensibilidad erótica normal (no débil ni intermitente). Los expertos aseguran que esta madurez biológica ha llegado a su punto a los 18 años en la mujer y a los 20 en el hombre.

b) La madurez sexual comporta también un aspecto biopsíquico: las llamadas «pulsiones parciales» se van sometiendo al primado de la pulsión genital. «El placer inherente a las zonas erógenas no genitales se vuelve preliminar al orgasmo. La pulsión sexual se pone al servicio de la reproducción» (Laplanche-Pontalis).

c) La madurez sexual entraña asimismo un fuerte componente psicológico. Paso a paso la dinámica psicológica orienta, cuando no es interrumpida ni desviada, hacia el amor sexual. En cualquier caso, esta dinámica es delicada y puede ser alterada bastante fácilmente por factores biográficos o sociales.

He aquí unos pasos o señales de maduracion:

- Las tendencias fusionales o aquellas otras que pretenden dominar o incorporar a la pareja como parte de sí mismo, se van diluyendo. 
- La propensión a vivir en el presente relaciones demasiado calcadas sobre el pasado (p. ej. Las anudadas en su día con el propio padre o madre) se difuminan.

- La sensibilidad y la ternura (todavía separadas con frecuencia al inicio de la pubertad) convergen en la misma persona deseada.

- Aparece la reciprocidad:

- el respeto al deseo y a la decisión del «partner»,

- el deseo de gozar se abre al deseo de que «el otro goce también».

- Vencidos los deseos narcísicos, la agresividad y los miedos, prevalece «el abandono recíproco de dos cuerpos, animados en verdad por un espíritu de benevolencia progresiva» (Duyckaerts)

- Emerge la tendencia psicológica hacia la fidelidad. En otras palabras, se anuda un triple vínculo:

- queda cancelado el miedo a caer en la esclavitud del otro. La persona se siente realizada ligándose a él;

- brota la propensión psicológica de prometer fidelidad en lo mejor y en lo peor por encima de los caprichos del deseo. A pesar de todo esto, conserva siempre el deseo un carácter errático, embridado más o menos espontáneamente por el amor;

- las personas unidas por el amor sexual «no pueden» vivir sin su «partner». La vida de uno se articula con la vida de la otra y viceversa. En este contexto se explicita el deseo de una descendencia nacida de ambos (Cfr. Duyckaerts o. c., pp. 303-309).

\section{5. ¿Antropología autosatisfactoria?}

Al pasar revista al conjunto de las reflexiones de los especialistas que he consultado sobre la madurez humana no puedo sustraerme a la impresión de que parecen revelar una imagen «demasiado equilibrada» y un tanto prometéica del hombre. Sus descripciones y construcciones mentales no se hacen cargo, en la medida necesaria, de que la crisis de la enfermedad, la angustia, la depresión, el vacío existencial, el sinsentido son tan humanas y tan familiares a todo hombre como el vigor físico y psíquico, la paz, la alegría, la esperanza, las experiencias de plenitud y la vivencia del sentido. Son signos de la precariedad y contingencia humanas. «El 
verdadero icono del creyente (y del hombre) no es Pedro caminando sobre las aguas hacia Jesús, sino Pedro a punto de hundirse, que grita al Señor "sálvame” y al que el Señor le agarra» (Bianchi).

\section{POSIBILIDADES Y DIFICULTADES SINGULARES PARA LA MADURACIÓN SEMINARÍSTICA Y PRESBITERAL}

Las reflexiones subsiguientes tienen como interlocutor intencional preferente las jóvenes generaciones presbiterales. Mi conocimiento vivo del mundo seminarístico ha ido perdiendo alguna actualidad. Espero, sin embargo, que el desenfoque de mi exposición no sea excesivo. Al fin y al cabo el espejo próximo en el que se miran los seminaristas mayores y en el que los formadores detectan los puntos fuertes y débiles de las actuales generaciones y de la misma formación impartida es la generación de los sacerdotes jóvenes.

Los sacerdotes somos seres humanos en edad adulta. Existe entre nosotros y las generaciones a las que pertenecemos un gran parentesco. Pero nuestro modo de vivir y trabajar tiene singularidades que no son periféricas. A este modo van a ser próximamente llamados los seminaristas. El sacerdote no es ni un simple caso particular del adulto ni una especie aparte. Desde esta perspectiva, es útil apuntar de qué modo específico se realizan en el presbítero algunos rasgos de la condición adulta.

\section{Amar y trabajar}

He aquí dos dimensiones capitales sin cuyo cultivo no cabe maduración humana. Para la mayoría de los mortales, el amor se concreta en una relación de pareja, de vida y de proyecto, que se prolonga y se completa en la formación de una familia o de una agrupación más o menos análoga. Para la misma mayoría de los mortales, el trabajo consiste en una profesión civil reconocida socialmente como tal y regulada laboralmente.

El presbítero vive esta doble dimensión trascendental de manera muy diferente a la mayoría de sus conciudadanos. Su manera de amar es célibe y no es por tanto compatible con una vida de pareja unida por el amor sexual. Su mundo de trabajo es también singular: la acción pastoral que, 
al margen del mayor o menor aprecio social que despierta, es cualitativamente diferente de cualquier trabajo civil y reclama ordinariamente una limitación y una renuncia a compromisos sindicales, políticos, culturales. ¿Es posible vivir el celibato sin estar condenado a la trilogía de males a los que nos viene condenando desde hace mucho una determinada literatura: la tristeza, la dureza, la rareza? ¿Es posible dedicarse a las tareas pastorales y sentirse realmente arraigado en la sociedad por un fuerte sentido de pertenencia y no embebido en el «mundillo eclesiástico»?

Es preciso que tomemos en serio las preguntas para ofrecer una respuesta honesta. La respuesta genérica va por este camino: cualquier opción de vida comporta elegir un valor y renunciar a otros. En este sentido, cada opción enriquece y empobrece. Esta doble y especial condición afectiva y laboral puede ser, al mismo tiempo, una dificultad y una posibilidad para la madurez humana. Que, en realidad, sea lo uno o lo otro depende de las actitudes y comportamientos que adoptemos ante ellas.

a) La vida célibe puede ser una dificultad para la maduración de un presbítero. Lo es para bastantes. Algunos de ellos vegetan en la doble vida. Algunos otros llevan consigo los signos de una notable insatisfacción y las marcas de sus frecuentes, casi crónicas, debilidades. Para otros el celibato es un intento honesto y un logro aceptable. Para un buen grupo es algo que forma estrechamente parte de su proyecto vital. Están real y básicamente identificados con él. Aunque lo viven también con cierto costo y una cierta tasa de debilidad, supone para ellos una liberación de otras preocupaciones y proyectos y un signo de su ofrenda plena al Señor.

Si para los dos primeros grupos la dificultad neutraliza y anula las posibilidades, para los dos segundos las abre notablemente. En primer lugar, un celibato bien vivido desarrolla notablemente el registro de la oblatividad y reduce también notablemente el registro de la demanda. Incluso bastantes de ellos encuentran en este tipo de existencia un sentirse centrados que poco o nada tiene que ver con el masoquismo ni con la huida de compromisos familiares más estrechos. En segundo lugar, un celibato que renuncia a una relación de vida, de comunicación, de goce y de proyecto con una mujer para poder formar «otra familia más amplia», introduce en la dinámica del amor una orientación genuinamente evangélica que le impide quedar «fijado» en unas pocas personas y le facilita abrirse a más 
personas y a los más necesitados. Oblatividad y apertura a la universalidad son dos frutos de un celibato bien asumido.

Con todo, la vida célibe es siempre un equilibrio delicado. Puede desvirtuarse. Tiene sus riesgos. Uno de ellos -dicho con palabras fuertes y graves- es «no amar de verdad a nadie». Con palabras suaves: vivir en la vida pastoral un amor de baja intensidad. Los afectos pasajeros y el aprecio a las personas en función de su utilidad para nuestros planes, incluso pastorales, son expresiones de esta debilidad. Otro riesgo consiste en acostumbrarse demasiado a la soledad célibe, enamorándose de los beneficios secundarios que ello comporta (espacios para mí solo, decisiones que no hay que compartir con nadie, etc.).

b) La vida laboral: la dedicación a la labor pastoral puede recortar el horizonte de vida de un hombre que, incluso por ser sacerdote secular, debería estar abierto y afectivamente implicado en la sociedad y sus problemas. Existe todavía un «hombre eclesiástico» que es la caricatura del «hombre eclesial». Le interesa de verdad la Iglesia y sólo la Iglesia. Pertenece de verdad a la Iglesia y sólo a la Iglesia. No le duele el presente de la sociedad. No le preocupa su futuro. No sé si esta especie se va extinguiendo. A veces me parece que no. Hemos de ser piadosos sin ser píos, eclesiales sin ser eclesiásticos, seculares sin ser mundanos.

Pero la labor pastoral puede enriquecernos porque es, antropológicamente, muy humana. Tenemos la suerte de dedicarnos a las personas. Tenemos la dicha de que bastantes quieren comunicarnos su profundidad. Conectamos frecuentemente «en vivo y en directo» con gente afligida y machacada. Compartimos también su dicha. ¿Está desarraigado un hombre así?

\section{Deseo y proyecto en la vida presbiteral}

En la vida de la mayoría de la gente, amor y trabajo, vida familiar y profesión, deseo y proyecto se condicionan mutuamente. La crisis familiar es más probable cuando hay crisis laboral. Viceversa, las vicisitudes del trabajo repercuten en el hogar. Pero el amor y el trabajo guardan cierta autonomía. Una vida amorosa buena puede paliar la insatisfacción en el trabajo. Un trabajo que me realiza puede hacer olvidar un tanto las preo- 
cupaciones del hogar. En suma: amor y trabajo, deseo y proyecto son dos raíles relacionados, pero diferentes, sobre los cuales descansa una cierta estabilidad.

La situación del presbítero es bastante diferente. El objeto inmediato de su amor y de su trabajo es el mismo: la comunidad cristiana a la que sirve. Ella condensa su trabajo y su amor. «El sacerdote tiene su corazón allí donde está su obra» (Leclercq). El cura se asienta sobre un raíl que es único. Esta especial identificación favorece la calidad y la intensidad de su dedicación. Unifica y gratifica la vida del sacerdote.

Pero allí donde reside su riqueza anida también su delicadeza. Toda crisis en una de las dos dimensiones influye muy sensiblemente en la otra. La crisis afectiva de un sacerdote puede hacer insufrible el trabajo ministerial. Los reveses pastorales pueden poner en cuestión la opción afectiva del celibato. La identificación entre deseo y proyecto (mayor en la vida presbiteral que en la vida corriente), es una fórmula de vida muy rica, pero muy delicada. El anclaje profundo en Dios y las relaciones amicales de mucha calidad son un activo inapreciable y un valioso apoyo.

\section{Especialmente vinculados a la Iglesia}

La Iglesia confía la Palabra, la Eucaristía, una comunidad cristiana concreta a la atención pastoral de un presbítero. Cuando contemplamos la densidad de este encargo, una conclusión se impone: ser sacerdote es un «cargo de confianza».

Un cargo de confianza es siempre un gran estímulo para la responsabilidad. Genera de ordinario autoestima, capacidad de decidir, paciencia, voluntad de superarse y aprender. No es de recibo la teoría en virtud de la cual un cargo (un «rol») empobrece a la persona robándole sensibilidad, sinceridad, libertad. El «personaje» (el rol) no es, sin más, un estorbo para la persona. Puede estimular muchas potencialidades dormidas. El rol de la paternidad ha despertado responsabilidad en parejas todavía no del todo asentadas. No existe una antítesis entre personas y rol. Sí una polaridad dialéctica llamada a ser enriquecedora.

Pero esta polaridad puede acabar en una polarización de la persona en el rol. El riesgo es mayor cuando el rol es muy consistente por la importancia del trabajo, por su relieve público, por el nivel de identificación que reclama con la institución, etc. Entonces puede (y suele a veces) darse, 
sobre todo en sacerdotes con bajo nivel de personalidad, un «endurecimiento en torno al rol». «El sacerdote corre el peligro de subirse sobre su propio rol para hablar y actuar desde allí, pero sin preocuparse de estar en sintonía con el camino de su gente y sin intuir lo que esperan de él, estableciendo una comunicación mucho más aseverativa que dialogal, más repetitiva que creativa, más circunspecta y precavida que explícita y cordial» (Card. Martini). Cuando sus feligreses le pregunten sobre cuestiones candentes y debatidas en la sociedad y entre los mismos cristianos, el rol puede inducirle a repetir machaconamente la doctrina de la Iglesia más que a intentar explicarla y fundamentarla convincentemente. En su deseo de edificar con su conducta, puede incluso traspasar el umbral de la sinceridad y ofrecer una imagen demasiado «oficial» e incluso inauténtica.

El camino consistirá en reforzar la propia persona como libre y como instancia de discernimiento. El amor a la Iglesia no debe ser fusional. Para amarla adultamente tengo que identificarme con ella y, al mismo tiempo, mantener una alteridad. La simple identificación genera fusión. La sola alteridad genera posturas distantes.

\section{La devaluación social de la función presbiteral}

El fenómeno recién descrito coexiste con este otro tan o más preocupante. Puede incluso influir sobre el anterior «calcificando» más su enfeudamiento en el rol. Es patente que la figura y el rol del sacerdote han descendido muchos enteros en la consideración social e incluso en la misma consideración de la comunidad cristiana. Es igualmente patente que este fenómeno repercute sobre la moral de los sacerdotes. Las ciencias humanas (Cattel) nos aseguran que el hombre y la mujer alimentan su autoestima en tres fuentes. La primera es la imagen globalmente positiva que uno tiene sobre sí mismo. La segunda es la evaluación positiva, objetivamente evaluada, de los frutos de su trabajo. La tercera es la estima que los demás profesan a su persona y a su obra. Cuando alguna de estas fuentes se seca, la autoestima puede quebrarse con alguna facilidad.

En estudio realizado recientemente en varias diócesis de Francia, el sacerdote psicoanalista T. Anatrella, observa bastantes casos sacerdotales de «desplome de sus proyectos y, lo que es más preocupante, de hundimiento de su imagen individual y social. Su fe no queda alcanzada, pero tampoco ejerce una función significativamente estimuladora». En estos 
casos todo parece indicar una regresión en los niveles de madurez, de equilibrio y de unidad interior adquiridos: una notable reducción del volumen de actividad o un activismo populista encubridor de un vacío doloroso; cuadros de ansiedad y depresión; conductas de connivencia con el alcohol; anudamiento de relaciones afectivas en colisión con el celibato; búsqueda de otros espacios de actividad socialmente más reconocidos; refugio cuasi exclusivo en grupos cálidos que le ofrecen apoyo, reconocimiento, etc.

He aquí la dificultad. ¿Y la posibilidad? La devaluación social de la función presbiteral aquilata en otros muchos sacerdotes la motivación por la que abrazaron el ministerio, las convicciones de fe por las que se mantienen en él y el sentido que sigue teniendo su fidelidad. Tal vez se ordenaron para otro mundo y otra Iglesia. No esperaban un panorama tan crudo. Ser valorados en su función y reconocidos en su utilidad fue tal vez una expectativa que reforzaba su opción. Las circunstancias les han despojado en gran parte de este componente. Pero han dejado básicamente intacta una opción no sólo mental y voluntarista, sino vital y pacífica y, aunque parezca paradójico, incluso gozosa. Como diremos más adelante, una tarea constante en la maduración humana y espiritual consiste precisamente en la purificación de los motivos. No son químicamente puros. Son «minerales». Llevan en sí vena y ganga. Los tiempos recios ayudan a algunos a separar la vena de la ganga.

No son tiempos de éxito, ni siquiera de gran fecundidad. Son, sobre todo, tiempos de fidelidad. Con todo, esta fidelidad desnuda debe revestirse de un cierto reconocimiento por parte de los responsables de la comunidad cristiana y del núcleo de cristianos más motivados. También un adulto maduro tiene, en cierta medida, necesidad de ser reconocido por aquellos a los que ama, a los que se siente vinculado, a los que ha entregado su existencia.

\section{5. ¿Ministerio arraigado o escasamente asentado?}

Una vocación no tiene solidez mientras no «prenda» en el mundo vivo de los deseos, las aspiraciones y los ideales del sujeto. La vocación auténtica asume ese fondo vital, aunque lo somete a una exigente purificación. Muchas adherencias narcísicas, temores infantiles, culpabilidades mal digeridas, sueños de omnipotencia se deshacen o se atenúan en este pro- 
ceso purificador. Pero es preciso que la vocación y misión asumidas sintonicen con el fondo vital del sujeto y se arraiguen en él. En caso contrario, o bien se instaura en él un notable coeficiente de insatisfacción, o bien la vocación y misión son superestructuras que no resisten la prueba de la verdad. Me viene a la mente la imagen de esos edificios de sólida estructura básica sobre la cual se ha construido un segundo piso, flamante pero endeble y mal entroncado con el primero. Son como aquellos que Jesús califica con estas palabras: «no tienen raíz en sí mismos y al llegar la persecución y la tribulación a causa del mensaje, enseguida sucumben» (Mt $13,21)$.

El fenómeno nada irrelevante de un número no desdeñable de secularizaciones muy tempranas, tiene algo que ver con este déficit. La experiencia de haber tratado muy de cerca durante mi vida presbiteral y episcopal a jóvenes sacerdotes que han abandonado el ministerio, me ha deparado la sorpresa de que bastantes de ellos se han desembarazado de su ministerio con una notable dosis de frivolidad, como quienes se desprenden de un apéndice artificial que no había hundido sus raíces en la carne y sangre de su ser. He conocido, sobre todo en tiempos anteriores, secularizaciones que eran la desembocadura de un largo proceso de combate, de sufrimiento, de culpabilización, de indecisión dolorida, de discernimiento. Personas a las que «se les partía el alma» al tener que dejar una parte de sí mismos (el ministerio) para abrazar otra parte de sí mismos que les requería con apremio: «defínete».

En los tiempos presentes, el proceso es con frecuencia más «indoloro» ( sin llegar a serlo del todo). En tales casos, uno tiene más que la impresión de que está ante una notable deficiencia en la construcción humana y espiritual de estas personas. Probablemente la teología del ministerio que han aprendido ha sido impecable. Probablemente han dedicado tiempo generoso a la oración comunitaria e individual. Probablemente han puesto interés en su iniciación pastoral. Y sin embargo, todo este «segundo piso» se ha venido abajo sin demasiado estrépito.

No pretendo interpretar este fenómeno que tiene que hacer pensar a los Obispos, a los formadores, a los presbíteros. Probablemente se debe a muchos factores. Sí me atreveré a señalar una pista: la relación formativa rara vez pasa del «piso segundo» para abajo. Albergo la sospecha de que muchos seminaristas se ordenan sin que, acompañados por algún formador, hayan bajado a esa «bodega interior» en la que residen los movi- 
mientos espontáneos de su persona. No llegan a conocer «la verdad de su propio deseo» (Lacan). Tal vez hacen examen de conciencia, pero no «examen de subconsciencia» (Marc Oraison). No han pasado por el «scanner» sus deseos más íntimos y más auténticos, sus temores, sus complejos, sus ambigüedades. No han llegado a esa transparencia comunicativa en la que han «enseñado todas sus cartas» a su formador espiritual. No han analizado ante otro y con su ayuda las motivaciones subyacentes a su opción. El piso que han construido tiene sus grietas. Cuando arrecia el temporal, se derrumba.

He aquí un trabajo que, si no se ha realizado en el tiempo de formación, debe ser abordado urgentemente en los primeros años de ministerio. Es aún tiempo propicio. Los motivos espontáneos pueden transformarse y abrirse a los motivos postulados por el ministerio. Pero necesitan ser elaborados con valor y paciencia en la oración, en el ejercicio del ministerio y en la comunicación transparente. No es preciso ni conveniente para ello (salvo en casos extremos) un psicoanalista llamado desde Oxford o desde Viena. Es tarea de un hombre de experiencia creyente, sagaz, generador de confianza, iniciado en la teología espiritual y sensible a las ciencias del hombre.

\section{6. ¿Corresponsables o protagonistas?}

Uno de los cambios más importantes y extendidos acaecidos en los últimos 30 años en la acción evangelizadora es el ensanchamiento del sujeto pastoral. El presbítero ha dejado de ser el protagonista casi único de la acción pastoral. La figura clásica del sacerdote, troquelado en la «soledad del corredor de fondo» y cuyos auxiliares eran meros ejecutores, es cada vez menos frecuente. Felizmente, una porción del laicado ha tomado conciencia viva y activa no sólo de su responsabilidad en la construcción de una comunidad verdaderamente humana, sino también de su corresponsabilidad en la construcción de la comunidad cristiana.

No sin problemas de diversa índole. Recojamos algunos registrados en el mundo presbiteral. La experiencia personal y algunos estudios que conozco se hacen cargo del dolor que supone para una parte del clero esta emergencia de laicos preparados en teología y pastoral, responsables de ciertas tareas eclesiales, capaces de voz crítica sobre las propuestas del presbiterio. Muchas veces son percibidos como una ayuda inestimable. 
Otras veces, como reductores del campo de responsabilidad directa de los sacerdotes «¿Sólo servimos para decir Misa y confesar?» Hay sacerdotes que se sienten un tanto acorralados y devaluados por los laicos incluso en la estima eclesial y personal.

En otros sacerdotes, la reacción consiste precisamente en mantener intacto su propio protagonismo y seguir tratando como simples colaboradores a aquellos que, por vocación y preparación, son capaces de ser corresponsables. Asentados en la convicción de que el sacerdote es guía y rector de la comunidad (lo cual es estrictamente cierto) se sienten a sí mismos como únicos responsables efectivos (lo cual es estrictamente incierto). A juzgar por la experiencia propia y ajena, esta actitud no parece exclusiva de una generación de sacerdotes que se educó en otro clima cultural por lo que respecta al ejercicio de la autoridad. Diríase que es compartido también por un número no insignificante de presbíteros jóvenes y de media edad. Un protagonismo desmedido, una hipersensibilidad a la crítica de los colaboradores, unas decisiones tomadas en solitario con demasiada frecuencia, parecen ser indicadores de tal actitud. No creo que la razón real suficiente de esta manera de comportarse se deba a la voluntad de corregir el democraticismo de algunos colaboradores ni de recuperar el papel singular y específico que, en una sana eclesiología, corresponde al presbítero. Tal vez los motivos de fondo son más caracterológicos o emotivos: la «voluntad de poder» (Adler), cierto narcisismo que nos conduce a protagonismos inmaduros y a un cierre a críticas interpeladoras.

El ensanchamiento del sujeto pastoral es una gran realidad propiciada por el Espíritu y postulada por la eclesiología y la evangelización. Es una gran ocasión para ensanchar también nuestra madurez humana, espiritual y pastoral. Coordinar, animar un equipo requiere una disciplina y una paciencia que pone a prueba nuestra virtud. Así lo es realmente en la vida y ministerio de muchos sacerdotes que dedican buena parte de sus energías a convocar a laicos y religiosos para que asuman responsabilidades, a ofrecerles los medios para su formación espiritual y apostólica, a formar con ellos un verdadero equipo pastoral y a asumir el papel aglutinador y orientador que les corresponde por su carisma presbiteral y por la misión recibida del Obispo. El ministerio pastoral no es exclusivamente nuestro. Es cierto que no es una realidad «unisex» compartida del mismo modo por pastores y colaboradores corresponsables. Pero hemos de compartirlo y pagar el peaje correspondiente: humildad ante la crítica, dedicación a 
aglutinar equipos cuya tentación es disgregarse, esperanza y aliento que anima en momentos de baja moral colectiva. Todo esto requiere madurez y virtud.

\section{Crisis de realismo}

Al principio de nuestro ministerio saltamos al terreno de juego con mucha ilusión, mucha pasión y una cierta inseguridad. El presbítero recién ordenado siente la necesidad de «medirse con la realidad», incluso para probarse a sí mismo de que «ha elegido bien». Esta necesidad le conduce a buscar más o menos conscientemente el éxito en su ministerio: comprobar que nuestra persona y nuestro trabajo son reconocidos como valiosos.

Ninguna espiritualidad realista puede ser inicialmente severa con esta querencia. Favorece notablemente la estima del sacerdote por su persona y por su trabajo. Facilita la identificación con el ministerio, al igual que unos primeros años satisfactorios de vida matrimonial refuerzan el mutuo compromiso de los cónyuges y les prepara para probables crisis ulteriores.

Con el paso del tiempo, el ansia de éxito debe ir dando preferencia a la búsqueda de la fecundidad. El empeño por la tarea bien realizada, la preocupación por la solidez y consistencia de su trabajo, el cuidado por preparar el futuro pastoral de su comunidad han de prevalecer sobre la búsqueda del éxito. Suele darse con frecuencia este saludable desplazamiento. No siempre. Algunos quedan como atrapados en su «narcisismo primitivo».

Llega, con todo, un momento, generalmente un poco más tardío, en el que la misma búsqueda de la fecundidad entra en crisis. Tras 10, 12, 15 años de ministerio, los logros pastorales se nos muestran precarios. La vida apostólica real rebaja las ilusiones que nos habíamos forjado sobre personas, grupos, iniciativas, estructuras. A medida que vamos entrando en el espesor de lo real, percibimos que nuestros esfuerzos son aportaciones muy modestas a los grandes procesos que dirigen la historia, modelan la sociedad y repercuten en la Iglesia. La propia experiencia de nuestra vida espiritual nos revela doloridamente la lentitud de nuestros progresos, la ambigüedad de nuestras motivaciones pastorales $y$, con alguna frecuencia, la persistencia y el incremento humillante de algunas debilidades y pecados. El ideal evangélico soñado para nuestra vida queda muy lejos. A esto se añade con frecuencia una aridez espiritual. Pensar en Dios, orar, apenas nos produce consuelo alguno. 
Es el momento de acentuar el registro de la fidelidad. A lo largo de su vida pública, Jesús fue comprendiendo cada vez más profundamente que el Padre le pedía fidelidad, no éxito inmediato e incluso por encima de la fecundidad a corto plazo. Este itinerario éxito-fecundidad-fidelidad es el propio del pastor. Hay que prepararlo desde el Seminario Mayor.

\section{TAREAS Y APOYOS PARA LA MADURACIÓN HUMANA DE PRESBÍTEROS Y SEMINARISTAS}

Al abordar este último capítulo de la conferencia, es preciso refrescar dos afirmaciones fundamentales.

a) Dada la unidad de la persona y la articulación entre la naturaleza y la gracia, existe una interacción mutua entre la maduración humana y la maduración espiritual y pastoral. Por este motivo enumeraremos y describiremos también algunos recursos de orden espiritual y pastoral como potenciadores de la maduración humana del pastor.

b) Hay recursos que son necesarios (por ej. la oración) o válidos para todos los sacerdotes, sea cual fuere la situación en la que se encuentren. No vamos a desarrollarlos aquí. Hay otros que son más específicos (aunque no exclusivos) de cada una de las fases de la vida presbiteral. Algunos han quedado aludidos a lo largo de la conferencia. Vamos a recoger, expresa y directamente, en las reflexiones siguientes, los recursos más indicados para los seminaristas mayores y los «sacerdotes jóvenes».

\section{Identificarse con su identidad}

He aquí la tarea clave para asegurar la maduración. El juego de palabras puede oscurecer la comprensión de su contenido. Sin duda que el ordenado y el mismo seminarista mayor, tienen en circunstancias ordinarias un grado importante de identificación con su vocación y misión. En muchos casos tal identificación tiene más intensidad que profundidad. Uno se hace sacramentalmente presbítero por la ordenación. La vida y trabajos de los primeros años le van haciendo existencialmente presbítero. En otras palabras: la unidad de todas las dimensiones de la persona en torno a la vocación y misión es una tarea progresiva y laboriosa. «Llegar a ser lo que soy: un cura», es algo más que un lema; es todo un programa. 
Identificarse con su identidad comporta para el presbítero joven un discernimiento de todos sus proyectos parciales (unos explícitos, otros un tanto soterrados) que pueden no ser coherentes con el concreto proyecto presbiteral. El presbítero no es el joven que se ciñe a sí mismo y va a donde quiere; otro le ceñirá y lo llevará a donde no quiere. En la ordenación ha aceptado libremente no disponer de sí mismo. Un gesto simbólicamente muy rico, incluso conmovedor, del rito de la Ordenación, rubrica esta actitud: el futuro presbítero pone sus manos en manos del Obispo. Se confía al Señor a través de la Iglesia. Se confía a la Iglesia a través del Obispo.

Identificarse con su concreta identidad presbiteral comporta asumir vitalmente el celibato. Tal aceptación ha sido siempre costosa. Hoy su recepción íntegra encuentra resistencias sociales que pueden repercutir en el joven presbítero y en el seminarista mayor. El celibato puede asumirse como entrega a la comunidad. Cuesta más aceptarlo como forma de entrega radical a Dios y como aceptación del Señorío de Jesucristo sobre nuestra vida sexual y afectiva. Cuesta más en nuestros días, caracterizados por una simultánea exaltación y banalización del sexo, descubrir el sentido siempre actual del celibato como signo de la vida alternativa del Reino de Dios.

Tal vez la dificultad mayor de los jóvenes sacerdotes y los seminaristas para identificarse con su identidad reside en que el joven de nuestros días pertenece más intensamente que nosotros a la época en la que estamos viviendo. Esta época desarrolla una sensibilidad verdaderamente nueva, que está suscitando una creciente e impresionante aceptación social incluso en una porción notable de la comunidad cristiana. Tal sensibilidad compartida contradice en muchos puntos capitales a la sensibilidad cristiana promovida por la Iglesia. El sacerdote joven y el seminarista mayor están situados en el punto de encuentro y de choque entre ambas sensibilidades. Pertenece a ambos mundos. Se siente interiormente habitado por dos lógicas diferentes y, en alguna medida, escindido entre ambas sensibilidades. Esta «fractura» entre experiencia social y experiencia eclesial no favorece la unidad interior ni la identificación con el ministerio. La penuria casi general de vocaciones y algunas secularizaciones tempranas pueden tal vez explicarse por esta doble pertenencia. Tienen más dificultades que otras generaciones anteriores para lograr esa unidad interior que es rasgo esencial de la personalidad madura y confiere a ésta una fuerza y una fecundidad mayor. 


\section{La comunicación transparente}

El contraste habitual de nuestra propia vida, incluso en sus dimensiones más íntimas, con un testigo adulto, libre y respetuoso, es uno de los más preciosos catalizadores positivos del crecimiento y maduración de una persona. Por desgracia no es, ni mucho menos, una práctica común, ni siquiera en nuestros seminarios. El pudor natural, el miedo a desmerecer ante el testigo, el no estar habituado a este ejercicio saludable, la escasez de testigos preparados y dispuestos a este acompañamiento se confabulan para que esta práctica, lejos de estabilizarse, vaya diluyéndose ya en los primeros años de ministerio. Una vida tan diferente a la del Seminario despierta, con frecuencia, «un hombre diferente» que tiene que volver a aprender a decirse a sí mismo y experimenta muchas veces un pudor mayor para comunicarse humildemente: «todo un cura y estos problemas».

El carácter benéfico de esta praxis es patente incluso como higiene psíquica. El paso al registro de la palabra humaniza y sosiega el mundo de los impulsos, deseos, fantasías, temores, comportamientos íntimos que, si no se comunican a otro, mantienen su carga pasional imperiosa. La introspección, por muy penetrante que sea, no tiene la virtualidad liberadora de la apertura «ante otro». Es asimismo expresión de honestidad consigo mismo, puesto que es condición de lucidez. Soportar la verdad sobre vosotros mismos se torna con frecuencia tan duro que preferimos enfundarnos en justificaciones y legitimaciones. «La memoria me dice: has obrado mal. El orgullo me dice: no has podido obrar mal: y el orgullo acaba acallando la memoria» (Nietzsche). Cuando omitimos la comunicación, fácilmente se crea en nosotros un fondo oscuro no exento de malestar y de un cierto sentimiento de culpabilidad.

La comunicación transparente es, asimismo, signo de nuestra apertura a Dios, de la entrega de todo nuestro ser al Señor. Quien se abre «como un libro», muestra un deseo eficaz de disponibilidad total que facilita su maduración espiritual. Quema sus naves defensivas.

La comunicación transparente es la respuesta proporcionada y necesaria a la confianza que la Iglesia deposita en el candidato. Éste ha de ofrecer a la Iglesia la garantía de saber «con quien se juega los cuartos».

Ha de ser total. No sólo hemos de comunicar lo que hacemos y sabemos, sino también lo que sentimos. No sólo de nuestro pasado, sino también nuestro presente y nuestras ambiciones, cálculos o temores respecto 
del futuro. Todo ello en lenguaje claro y directo, sin evasiones a la formulación genérica o técnica que rebajan el poder terápico de la comunicación. Puede realizarse en un contexto de entrevista que desemboca en una confesión sacramental. Pero ésta, sin desdoro de su densidad sacramental, realizada en un contexto anónimo o episódico no suele suplir la virtualidad maduradora de la entrevista transparente.

\section{La armonía entre interioridad y exterioridad}

Más que dos capítulos de actividades diferentes, interioridad y exterioridad son dos dimensiones de toda actividad verdaderamente humana. Las ciencias humanas nos han ayudado a distinguir entre la conducta (la cara externa perceptible) y la vivencia (la cara interna). Ambas componen el comportamiento humano.

Cualquier comportamiento entraña connaturalmente consigo, en una medida u otra, ambas dimensiones. Pero hay comportamientos que reclaman más la exterioridad que la interioridad y viceversa. Organizar una catequesis y dirigir un retiro espiritual no interesan en la misma medida nuestra interioridad y nuestra exterioridad. En consecuencia el equilibrio entre las dos dimensiones está reclamando también un equilibrio entre estos dos géneros de actividades.

La vida del sacerdote sufre una modificación bastante radical al salir del Seminario e iniciar su ministerio. Una de estas modificaciones consiste precisamente en invertir la proporción entre las tareas que favorecen la interioridad y aquellos que propician la exterioridad. En el Seminario, la reflexión prevalece sobre la acción, la revisión sobre la programación, la plegaria sobre las responsabilidades apostólicas. En los primeros compases de la vida pastoral, corremos el riesgo de invertir desmesuradamente la proporción entre las dos dimensiones antedichas. Las ansias de actividad y los reclamos interminables del apostolado suelen provocar con frecuencia un desequilibrio preocupante. El riesgo de «vivir mucho»y «moler poco» no es, en esta fase, nada imaginario.

Al principio «no pasa nada». Pero transcurridos los primeros años, la ansiedad producida por nuestros proyectos y trabajos puede volvérsenos crónica. La insatisfacción por los logros, lacerante. El descontento por la pobre respuesta a nuestros desvelos, dolorosa. La oración oxigenada en un primer momento por el estímulo del ministerio, pobre e intermitente. Pue- 
den emerger viejos demonios dormidos e incluso desconocidos en la vida seminarística.

La vida del presbítero no puede ser ni grata, ni fecunda, ni auténtica si no logra, por la acción del Espíritu y nuestra colaboración, una armonía entre interioridad y exterioridad, que se necesitan mutuamente como el alma y el cuerpo. Es preciso que las actividades que favorecen la interioridad (la oración, la reflexión teológica y pastoral, los retiros espirituales, la comunicación de la propia interioridad, la amistad, el contacto con la naturaleza, la escucha de la música, la contemplación del arte), se reconcilien, en un proyecto de vida concreto, realista, contrastado y periódicamente evaluado, con las actividades que inducen a la exterioridad como la labor de cada día, los programas, los desplazamientos, los horarios rotos, la multiplicidad de focos que reclaman la atención, la dispersión de las actividades, las urgencias inesperadas, el ritmo apresurado que crea ansiedad.

Para mantener este equilibrio es muy deseable que los jóvenes sacerdotes «rueden» junto a alguno más adulto que sea humana, espiritual y pastoralmente rico. En el contraste diario con él templan sus idealismos, encajan positivamente las lecciones de la vida, asimilan sabiduría pastoral y aprenden a leer la realidad eclesial y social con ojos de pastor.

\section{Clarificar y purificar las motivaciones}

La experiencia del trato en profundidad con seminaristas y sacerdotes jóvenes me ha conducido a distinguir con algún cuidado razones y motivos. Razones son aquellos argumentos temáticos con los cuales justificamos nuestras opciones (p. ej. la elección del ministerio sacerdotal) como surco de nuestra vida. Suelen presentarse con frecuencia con una formulación precisa, teológicamente ajustada, espiritualmente atractiva y pastoralmente correcta. Motivos son aquellos movimientos vitales que proceden de nuestra afectividad, de nuestro mundo pulsional, de nuestros mecanismos defensivos, de nuestros sueños, de nuestras aspiraciones a realizarnos, de nuestro idealismo, a veces formulados de forma genérica o imprecisa, otras veces simplemente barruntados, en ocasiones incluso inconscientes. Pero son factores que condicionan y alimentan una opción vocacional.

Una de las tareas delicadas del sacerdote consiste en comprobar la coherencia y parentesco estrecho entre las razones y los motivos. Las primeras 
suelen aparecer más impecables. A veces, demasiado. En estos casos, cuando uno las oye formular, le suenan a algo aprendido, dicho «de memoria». No resuenan dentro de la persona. No dejan entrever por ningún resquicio la adhesión vital y cálida del sujeto. No permiten barruntar los temores, las dudas, las incoherencias. Con una imagen anteriormente utilizada, diríamos que pertenecen al «segundo piso» del edificio vocacional.

Sólo si razones y motivos se reconcilian (aunque nunca del todo), podemos vaticinar la solidez del edificio vocacional. Hacer que los motivos coincidan con las razones es el objetivo de una vocación sólida y de una persona integrada, dotada de unidad interior, es decir, madura.

Los motivos pueden ser múltiples: un idealismo generoso, una afinidad por los pobres descubierta en el servicio, una fina sensibilidad creyente, un atractivo hacia Jesucristo y una voluntad de seguirle, una experiencia gozosa de fe que siente el deseo de transmitir. Todos estos motivos son reales. Con sus adherencias idealistas o narcísicas, pero reales. Pero también encontramos en este repertorio de motivos, algunos de signo diferente: un afán de protagonismo, un temor a la intemperie de la vida civil, un sentimiento de culpabilidad del que uno se quiere redimir, un miedo a no ser capaz de lograr y mantener el amor y la estima de una mujer, una incomodidad ante mi propio cuerpo al que percibo inatractivo, una homosexualidad latente o patente, una fijación excesivamente fuerte en la figura materna, etc.

No nos sorprende a estas alturas que estos motivos estén entremezclados. Son como el mineral, que se compone de vena y de ganga.

Quien piense ingenuamente que él se ha entregado al Señor y a los demás por pura generosidad, sin buscar ninguna compensación ni beneficio secundario, se llevará una decepción cuando descubra que al buscar a Dios se buscaba también a sí mismo. Hemos de renunciar al orgullo de haber entregado a Dios «la oveja sin mancha» y tener la humildad de haberle ofrecido «la oveja coja». Es más positivo y más evangélico ponernos a purificar nuestra motivación. La experiencia del acompañamiento humano y espiritual y las ciencias humanas nos dicen que es una tarea posible. Allport habla de la autonomía funcional de los motivos, de su capacidad de transformarse. Cita un ejemplo muy ilustrativo: un pescador empedernido del presente pudo comenzar a pescar no porque le atrajera la pesca, sino porque en su infancia quería acompañar a su padre. Al cabo del tiempo, el deseo de ir con su padre se ha transformado en pasión por la pesca. 
Conocer los motivos reales es el primer paso necesario. Necesitamos a veces ayuda exterior. Los motivos incluso más oscuros se revelan en nuestros comportamientos o en sentimientos de malestar más o menos intolerables si tenemos lucidez y sagacidad para registrarlos.

Alentar los motivos auténticos en el pensamiento, en la praxis, en la oración, es el paso siguiente. Todo este trabajo está regado e impregnado por la acción del Espíritu.

\section{Aprender el lenguaje célibe del amor}

El amor puede expresarse de muchas maneras. Ninguna de ellas es puramente espontánea, connatural. Todas reclaman un aprendizaje. También el amor preconyugal y conyugal. Duyckaerts escribió un libro precioso que se titula La formation du lien sexuel (Dessart, 1962), en el que describe el itinerario del amor de pareja desde sus primeros balbuceos, con sus miedos, sus desconfianzas, su deseo de mostrarse a sí mismo capaz de conquista, su voluntad de seducir, su temor a ser acaparado, etc., hasta la unión madura de dos personas que han crecido juntas, pasando por unas etapas en las que van reconociéndose, confiándose, entregándose, pacificándose. La entrega corporal y espiritual confiada y la mutua benevolencia son los signos de una unión lograda.

El amor célibe no puede sustraerse a este aprendizaje. ¿En qué consiste aprender a amar con un corazón célibe?

a) En primer lugar es preciso conocer experiencialmente lo que es en concreto ser célibe. Antes todavía que conocer y experimentar el valor del celibato y los motivos para serlo. Conocer lo que es el celibato real, no el celibato soñado. Esbocemos algunos apuntes:

- El vacío que origina la condición célibe es específico: vacío de mujer, de compañía femenina íntima y constante, de paternidad, de gozo y goce sexual. Este vacío, expresado en el reclamo de nuestro corazón y nuestro cuerpo no se satura del todo con ninguna otra realidad de este mundo. Ni la adhesión creyente, ni el amor a la comunidad, ni las satisfacciones pastorales, ni la amistad humana, ni la vida familiar rica, ni la ternura filial hacia María, ni la relación cercana con el Obispo suplen y «llenan» la soledad existencial del célibe. Debemos saber esto; debemos aceptarlo. Es necesario asumirlo para no embebernos en la ilusión romántica de un celibato imaginario... e insatisfactorio. 
- Sin embargo, todas estas relaciones son muy importantes para asumir positivamente (incluso con gozo) la soledad propia del celibato. Hemos de procurar la calidad de todos estos vínculos saludables. Son una preciosa ayuda para mantener el celibato y crecer en él.

- Tal vez lo más difícil del celibato es su duración por toda la vida: el «diu perseverare in accepta Dei gratia» (Concilio de Trento). La experiencia de muchos llega a sostener que, durante la juventud, el celibato podría llevarse más ágilmente que en la madurez. En esta última fase el célibe viviría a menudo secretamente la impresión de ir dejando pasar «los últimos trenes» que podrían conducirle al matrimonio. En esta fase, muchos realizarían de hecho, existencialmente, la renuncia irrevocable al amor conyugal y al deseo genital. Por otro lado la duración reclamaría una energía sostenida para contrarrestar la tendencia tan humana a la fatiga y a la pérdida de entusiasmo juvenil.

b) En segundo lugar, es preciso ir asumiéndolo. En general, los signos de la vocación célibe amanecen más tarde en el interior de los seminaristas que los signos que revelan nuestra vocación ministerial. Cuando la pulsión sexual crece y el vacío interior de no amar ni ser amado de manera singular y única por una persona singular se vuelve lacerante, nuestra identificación con el ministerio, con la comunidad, con Cristo Pastor y sus actitudes fundamentales nos ayudan a llevar el celibato. Pero el celibato no puede ser «el salchichón» que entra en la cesta de Navidad en la que lo que verdaderamente apreciamos son los vinos del Duero, el coñac Cardenal Mendoza, los turrones finos de confitería, el jamón de Guijuelo... y junto a ellos, «el salchichón». Asumir el celibato no es «llevarlo porque cae en la cesta», sino porque es valorable y valorado por sí mismo.

- Asumir el celibato entraña situarlo en el contexto del seguimiento, como una dimensión del seguimiento. El contexto connatural del celibato es la vida entera en el seguimiento. "Santo Tomás de Aquino ve los tres consejos evangélicos ligados en una unidad inescindible. Si no se acepta en su integridad la llamada evangélica al seguimiento, el celibato se nos antojará un cuerpo extraño. Y si esto no sucede, el celibato no puede ser signo convincente ni puede ser vivido con aquella alegría que es característica de los discípulos de Cristo» (Greshake).

A pesar de las afirmaciones de publicaciones cargadas de prejuicios y privadas del mínimo rigor científico, esta identificación con el celibato es un hecho real y frecuente. El porcentaje de sacerdotes que viven honesta- 
mente su celibato es notable. Un intento honesto y un logro aceptable. Los problemas existentes en muchos casos son de orden menor. No afectan gravemente ni a la vida espiritual, ni a la entrega apostólica ni a la alegría de su vida sacerdotal, aunque sí la merman y la palidecen en parte. Otros viven incluso elegantemente y con gozo la consagración de su corazón al Señor. También existe un número no exiguo de sacerdotes con problemas importantes en esta materia. Ayudar a estos sacerdotes es una tarea coherente con la fraternidad sacramental del presbiterio. Hay también un coeficiente no desdeñable instalado habitual o intermitentemente en la doble vida.

- Asumir el celibato entraña también asomarnos a los motivos reales que pueden estar inspirando, tal vez sin que sean del todo conscientes. Aquí es aplicable cuanto acabamos de decir sobre la clarificación y purificación de las motivaciones.

- Asumir el celibato significa también volver a tomarlo en las manos, para dejarnos curar por Dios cuando la inexperiencia, la seducción súbita, el «pronto compulsivo», el enamoramiento encantador y turbador lo ha averiado, noqueado. Tomarlo en las manos sustrayéndose, activa y pacientemente, mediante la oración, la comunicación y la distancia, al «atractivo irresistible» de esa experiencia que lamentamos.

Estas debilidades son realmente posibles porque, en el celibato, nuestro corazón siempre alberga un determinado coeficiente, siquiera mínimo, de ambigüedad. «Hemos de orar porque nuestro corazón nunca está entero». Podemos tranquilizarnos a veces diciéndonos que nuestra voluntad está neta y firmemente decidida, pero que nuestros impulsos, que son mucho menos «nuestros» que la voluntad, no acaban de acallarse. No. La ambigüedad pasa por el mismo corazón del hombre y lo alcanza en mayor o menor medida. Queremos ser célibes y, al mismo tiempo, no acabamos de resignarnos a serlo del todo. Cuando la tasa de ambigüedad es muy alta, los problemas (enamoramiento, deslices de conducta) se multiplican. Dos personas teóricamente en posición semejante, tendrán una tasa de dificultades muy diferentes según sea mayor o menor la ambigüedad de su propio corazón.

El celibato no es, pues, algo realizado al $100 \%$, sino una conquista progresiva, trabajada por dentro por la acción de la gracia. La ambigüedad de la opción se va desdibujando paso a paso hasta que el «querer ser célibe» domestique a ese «no resignarse del todo a ello», que es tan frecuente en nuestra condición concreta. Es importante auscultar si nuestro celibato es 
ascendente o descendente. Incluso la significación moral de una misma falta objetiva resulta diferente cuando ocurre en un proceso de maduración gradual o en un itinerario de deterioro progresivo.

- Asumir el celibato significa adentrarnos en su significación teológica, espiritual, ministerial. Huelga desarrollar este punto, por considerarlo bien conocido.

c) En tercer lugar, es preciso ir cultivándolo.

Las relaciones humanas cuyo componente principal es la oblatividad son vías de aprendizaje para el celibato. Así, por ejemplo, la amistad; el trato servicial y afectuoso con personas mayores, desvalidas, enfermas; la colaboración con causas generosas. Todas estas relaciones propician el cultivo humano positivo de la castidad célibe.

Cultivar entraña también protegerlo.

- Los estímulos eróticos del ambiente, si son masivos e insinuantes, dificultan sensiblemente la vivencia del celibato. Alimentan una vida sexual imaginaria cuya morosidad les parece negativa incluso a muchas instancias que se caracterizan por su laxitud moral en esta materia. Vivir en una sobriedad de estímulos eróticos, apagar la TV en determinados momentos, controlar nuestro «Internet», retirar una mirada a tiempo... demuestra una sensatez propia de aquel que no quiere agravar innecesariamente las dificultades.

- La sobriedad en el lenguaje gestual con mujeres es otra regla de sabiduría nada desdeñable. Hoy los usos sociales han liberado notablemente este intercambio gestual. El beso, el abrazo, etc. resultan más connaturales. Pero hemos de ser lúcidos y honestos. Tal liberalización permite un «tráfico de armas clandestino». Puede deslizarse nuestra sensualidad bajo el disfraz de unos signos inocentes. Cada uno conoce bien cuando sucede esto. No debemos ser obsesivos, pero sí lúcidos.

- La oración sostenida y humilde es un alimento necesario. El celibato es una gracia especial. Perdurar en él es imposible «sine speciali Dei auxilio». En palabras de Bonhoëffer, es «una gracia cara». La oración confiada y frecuente por nuestro celibato y por el de otros hermanos constituye una actividad perentoria que no hemos de descuidar. En pocas áreas de nuestra vida experimentamos más vivamente la fragilidad. «Cuanto más 
imposible se considera por no pocos hombres la perfecta continencia en el mundo de hoy, tanto más humilde y perseverantemente pedirán los presbíteros, a una con la Iglesia, la gracia de la fidelidad que nunca se niega a los que la piden» (PDV 29).

\section{Conclusión: la madurez humana y espiritual de San Francisco Javier}

No debo acabar mi reflexión sin volverme a Francisco Javier. No puedo ni quiero dispensarme de un elemental apunte final sobre el itinerario psicológico y místico de este gran apóstol. Su conversión supone la ruptura de su acariciado proyecto vital, inspirado por la ambición. Como sucede en los hombres del Espíritu, esta ruptura no es en modo alguno la ruina de su riqueza humana. En medio de esta ruina solo aparente, renace, transfigurado y purificado, el temperamento de Javier. El ambicioso va a transformarse en hombre de deseos y el hombre de deseos en hombre del Espíritu. El tacto y el discernimiento de los maestros del espíritu como Ignacio de Loyola saben siempre orientar el crecimiento espiritual no solo sin aplastar la riqueza humana de los convertidos, sino poniéndolo al servicio del concreto proyecto de Dios.

Intuyo que el dinamismo psicológico del que la gracia de Dios se valió en la transformación de Javier fue la sublimación, en virtud de la cual las aspiraciones nativas de su rica humanidad, al cambiar de objeto y objetivo inmediatos, se unificaron en torno a Jesucristo y su Proyecto salvador. Todo hace pensar que esta inversión de sus energías vitales fue masiva. El temperamento impetuoso, apasionado, radical, directo de Javier era un terreno abonado, como el de Pablo, para esta unidad interior.

Javier es un hombre muy afectivo y muy afectuoso, que recibe con muchas lágrimas, por ejemplo las escasas cartas que pudo recibir de San Ignacio y responde a ellas con la misma efusión. Esta afectividad se condensa y se sublima en la relación con las comunidades que suscita, con sus colaboradores, en la cercanía a los enfermos... y en los consuelos de la oración que adquirieron relieve verdaderamente místico, sobre todo en las horas nocturnas. La palabra «sentir», heredada de San Ignacio, le es muy querida. Como en su maestro no es ni puro conocimiento ni puro sentimiento sino un encuentro que implica a toda la persona y una experiencia existencial concreta y honda. 
Javier es un idealista en el sentido noble y en el sentido limitativo de esta palabra. Cuando descubre un nuevo horizonte, siempre generoso y discernido ante Dios, su entusiasmo le conduce inicialmente a idealizar la realidad y a ensanchar las posibilidades de alcanzarla. La imagen previa que se crea del Japón y de China, por ejemplo, parecen revelar esta tendencia. No es inmune a la decepción y al desencanto que le produce esta rebaja de la realidad. Pero su temperamento y su virtud le conducirán a sobreponerse a la decepción, ratificándose en su empeño y ajustando los planes iniciales con un realismo muchas veces admirable a los postulados de la realidad. Lo importante es hacer lo que se puede, lo que Dios quiere, y sembrar para el futuro. Javier, dócil a la experiencia que va adquiriendo, modifica sus juicios al compás de ella. Negocia con la realidad. Sabe entrar por la ventana de las aspiraciones de sus interlocutores para salir por la puerta de la voluntad de Dios y de la evangelización.

Es probablemente atinada la identificación de Javier formulada por José $\mathrm{M}^{\mathrm{a}}$ Pemán: «el divino impaciente». Su natural impulsivo no aguanta fácilmente demoras, esperas, obstáculos mezquinos, miedos poco evangélicos, injusticias flagrantes, contratestimonios demoledores. La paciencia es en él una pasión, es decir, un verdadero sufrimiento, un freno a su voluntad de hacer mucho. El amor pastoral a su gente le ayuda a digerir su impaciencia. Hay que «saber aliviar sus flaquezas y llevarlas con mucha paciencia».

El natural alegre y confiado de nuestro hombre va a encontrarse con unas tasas de dureza física, de fiebres obstinadamente intermitentes, de persecución, de desilusiones y fracasos, de peligro de muerte. Una fuerte convicción se ha abierto paso en él: ser apóstol de Jesucristo es ser «su compañero en las penas». Sabe que sin esta convicción el apóstol retira pronto su mano del arado. Esta convicción y el consuelo de la oración hacen que, en las peores privaciones, Francisco Javier compruebe que su natural alegría se va transformando en un gozo que va ganando en profundidad. «Al fin termina por tener sus raíces en capas tan hondas que ya no hay nada que le pueda turbar» (León Dufour). Desde esa experiencia contagia gozo y lo promete a quien se embarca en su misma aventura espiritual.

Llevado por su voluntad evangelizadora y su obediencia, Javier ha marchado a las Indias ingenuamente confiado en que no solo no le faltarán colaboradores en abundancia, sino consejo, contraste, instrucciones, apoyo explícito desde Europa. Poco a poco se va convenciendo de que, en 
la práctica, está casi solo. La soledad le hizo sufrir. En ese dolor echa raíces en él la confianza, el apoyo existencial solo en Dios. Solo, abandonado prácticamente de todos, morirá musitando en su lengua materna su súplica al Dios misericordioso y a la Madre del Señor.

Sobre todo en sus últimos años, Javier casi nos sorprende, como otros santos, al expresarnos reiteradamente sus sentimientos de indignidad moral y de impotencia apostólica. A los que no somos santos nos pueden parecer exageraciones, retóricas o desmesuras patológicas del sentimiento de culpabilidad. "Estando fuera de mí-escribe a Ignacio-no conocí muchos males que había en mí hasta que me vi en los trabajos y peligros de Japón». El sentir así la propia miseria no es gracia que reciben todos. Y al P. Rodríguez: «Ruegue a Dios Nuestro Señor que me dé gracia de abrir camino a otros ya que yo no hago nada». Esta experiencia le forja el mismo tiempo en la humildad y le arraiga en la confianza en Dios. Humildad y confianza son el mensaje de Javier a los apóstoles de hoy, de mañana, de siempre. 